\title{
Research on the Current Situation and Countermeasures of Children's Sex Education in the Kindergarten of Dalian
}

\author{
Lina Zhang ${ }^{1}$, Dongqing Bai $^{1}$, Shuang Liu $^{2}$ \\ ${ }^{1}$ Teachers' College Shenyang University, Shenyang, China; \\ ${ }^{2}$ Tao Xingzhi International Kindergarten, Shenyang, China.
}

Keywords: Children; sex education; current situation; countermeasures

\begin{abstract}
This paper aimed to investigate children's sex education in the kindergarten of Dalian, and it proposed the improving strategy through analyzing current situation to enrich the related contents and improve the relevant methods so as to promote children's healthy growth. This research randomly selected seventy teachers and forty children's parents from four kindergartens in Dalian to be the survey objects. The method of investigation was mainly adopted to make research and analysis with current situation, problems and reasons of children's sex education. Furthermore, it put forward the countermeasures, namely, to deepen the homeland assistance, transform the concepts about sex education of teachers and parents, make out the related outlines, create the atmosphere and launch the related courses for teachers to enhance teachers' professional knowledge, break up the inherent pattern and seek the new methods of children's sex education.
\end{abstract}

\section{Concept Analysis and Definition}

\subsection{Sex}

The explanation of sex in terms of biology is that sex is an expression of people's physical form and ability. The biological differences between men and women are determined by the sex chromosomes. The definition of gender is complex, including sexual skills, health, morality, education, psychology and knowledge.

\subsection{Sex education}

Sexual education, referring to people's reproduction, life, physical need and sexual behavior, can be divided into narrow and broad aspects. In the narrow sense, it is oriented with the promotion of sexual physiology, sexual society, cultural connotation, sexual health and prevention of sexual disease. And in terms of broad sense, it includes gender awareness, socialization and equality. Sexual education is a lifelong education that helps people establish correct beliefs, values, attitudes, sexual identity and relations as well as intimacy ${ }^{[1]}$.

\subsection{Children's sex education}

Children's sex education means that teachers make out corresponding sex education content according to different characteristics of children's physical and mental development at different ages. Children can easily know the sex knowledge from sexual physiology, psychology and social life so as to promote children's healthy development and help them adapt to society[2].

\section{Investigation on the Current Situation of Children's Sex Education in Dalian}

\subsection{The target and object of the investigation}

This paper aimed to investigate children's sex education in the kindergarten of Dalian, and it proposed the improving strategy through analyzing current situation to enrich the related contents and improve the relevant methods so as to promote children's healthy growth.

This research randomly selected seventy teachers ( 9 male and 61 female) and forty children's parents from four kindergartens (one public and three private) in Dalian to be the survey objects.

\subsection{Methods of investigation}

This research mainly adopted the method of literature and investigation to study and analyze children's sex education in the kindergarten. 
There were 110 questionnaires given out, 95 recycled and 80 valid. SPSS20.0 was used for statistical analysis.

\subsection{Contents of investigation}

This investigation mainly included the sex education attitudes, contents, methods and master degree of related knowledge of the relevant teachers and parents.

2.4 Analysis of current situation of children's sex education in Dalian

2.4.1 Teachers' and parents' attitudes towards children's sex education

Table 1 Attitudes towards children's sex education

\begin{tabular}{c|c|c|c}
\hline Age Interviewee & $\mathbf{3 \sim 6}$ & $\mathbf{6 \sim 1 2}$ & $\mathbf{1 2 ~ 1 8}$ \\
\hline Parents & $10 \%$ & $15 \%$ & $66.4 \%$ \\
\hline Teachers & $53.33 \%$ & $27 \%$ & $15 \%$ \\
\hline
\end{tabular}

In the questionnaire, only $10 \%$ of the parents and $53.33 \%$ of related teachers believed that sexual education should be carried out between 3 and 6 years old, while $66.4 \%$ of the parents and $15 \%$ of the teachers held the belief that the age of sexual education for children should be between 12 and 18 years old.

2.4.2 Teachers' and parents' attitudes towards children's sexual problems

Table 2 Attitudes towards children's sex problems

\begin{tabular}{c|c|c|c|c}
\hline $\begin{array}{c}\text { Problems } \\
\text { Interviewee }\end{array}$ & Instantly stop & $\begin{array}{c}\text { Have the } \\
\text { desire but no } \\
\text { the ability to } \\
\text { answer }\end{array}$ & $\begin{array}{c}\text { Transfer the } \\
\text { topic }\end{array}$ & $\begin{array}{c}\text { Positively } \\
\text { answer }\end{array}$ \\
\hline Parents & $65.8 \%$ & $10 \%$ & $20 \%$ & $3 \%$ \\
\hline Teachers & $60 \%$ & $15 \%$ & $18.7 \%$ & $6.1 \%$ \\
\hline
\end{tabular}

In the questionnaire, when children asked sexual questions, $60 \%$ of the teachers and $65.8 \%$ of the parents selected to instantly stop and $24.8 \%$ of the teachers and $10 \%$ of the parents want but have no ability to answer the question. Only 3\% of the parents chose to make a positive reply.

2.4.3 Sex education contents of teachers and parents on children

In the questionnaire, children's teachers paid more attention the construction of children's psychology and awareness of their gender role and sexual protection; while parents attached more importance to the preliminary awareness of children's sexual knowledge but lacked the education about sexual protection awareness.

2.4.4 Methods for teachers and parents to implement children's sex education

Table 3 Methods to implement children's sex education

\begin{tabular}{c|l|l|l|l}
\hline $\begin{array}{c}\text { Methods } \\
\text { Interviewee }\end{array}$ & Textbooks & $\begin{array}{c}\text { Parents' } \\
\text { teaching }\end{array}$ & Audio-video & Daily lives \\
\hline Parents & $5 \%$ & $10 \%$ & $10.6 \%$ & $74.4 \%$ \\
\hline Teachers & $10 \%$ & $8 \%$ & $80.5 \%$ & $1.5 \%$ \\
\hline
\end{tabular}

In terms of selecting the sexual education method, $80.5 \%$ of the teachers chose audio-video, while only $10 \%$ chose textbooks. And $74.4 \%$ of parents selected the daily lives, such as distinguishing the hairstyles and clothes between boys and girls, and distinguishing male and female toilets.

2.4.5 Teachers and parents’ master degree about the knowledge about children’s sex education 
From the aspect of sexual education knowledge, the writer made the questionnaire survey with teachers and parents about the life origin, gender role, sexual organs and protection. The data showed that they chose to learn a little, but more than half the teachers and $70 \%$ of the parents didn't have systematic knowledge. It is not hard to see that teachers and parents had limited sex education knowledge and rather low education level.

\section{Analysis on the Existing Problems and Reasons of Children's Sex Education in Dalian}

\subsection{Parents doubted the existence of children's sex education}

The following is part of the interview. J represents the parents and B represents the author.

B: Hi! How old is your child?

$\mathrm{J}$ : Hi! He is six years old.

B: What's your attitude towards the sex education courses offered by the kindergarten?

J: I am quite serious at this point. The child is so young that he has no need to have such course. After all, he still cannot understand the adult world. Too early letting children touch with the adult world is exploiting their "purity" and giving them wrong indications to make them imitate adults in advance.

This parent above has some misunderstandings about children's sex education, believing that sex education will promote their early puberty. The investigation of UN with developed, developing and backward countries showed that children's sexual education deferred the age of children having sexual behaviors ${ }^{[3]}$. Therefore, scientific, correct and professional attitude is of great significant to imparting the sex education knowledge to children and helping them get more healthy development.

\subsection{Teachers have concerns about children's sex education}

Children mainly learn knowledge from their teachers. But their parents are the most concern for teachers teaching sex knowledge. Lots of parents have narrow sex education thoughts, wrongly regarding the sex in the adult world as that of children's sex education. In order to avoid the conflict, teachers largely reduce the activity of children's sex education. Secondly, teachers seldom positively talk about sex with children because of their limited abilities and levels. In the face of children's questions, many teachers are unable to use professional terms to answer, thus imperceptibly casting a veil over the topic of sex.

\subsection{Teachers have insufficient knowledge of children's sex knowledge}

The following is the content of teacher interview. J represents the teacher and B represents the author.

J: What do you think is the biggest obstacle for children's sex education?

B: The child from parents' sexual relationship.

J: Do you mean that it's uncomfortable to talk about sex with children?

B: Yes.

Obviously, this teacher above didn't have a scientific understanding of mastering children's sex education knowledge. The reason is that the nation didn't set up standard teaching outlines and requirements with children's sex education, and the kindergarten failed to make out corresponding systematic training and testing system.

\subsection{The method of sex education adopted by teachers is single}

From the method of sex education adopted by the kindergarten in Dalian, teachers can only find some materials and adopt single education method due to lacking the requirement of systematic teaching methods. Teaching only with the materials concluded by the picture books will just make sex education keep still and cannot get better development.

\section{Countermeasures of Children's Sex Education in the Kindergarten of Dalian}

4.1 Deepen the mutual assistance of our homes and change teachers' and parents' concepts of sex education

Parents are the best teachers for children, and children's learning requires mutual understanding and communication between parents and teachers. It has been observed that few parents and teachers discuss 
sex with young children. However, sex is innate, and it is inevitable for children to know sex. Children's sex education is to let children know and understand sex, know the private places and protect themselves so that they can respect others and themselves. Therefore, teachers' and parents' concepts of sex education will directly affect the whole-life development of children.

"School education is the social activity launched by the whole staff and special institutions, with the features of nomad, system and organization, which can directly influence the physical and mental development of people received education."[4] Therefore, the related teacher are supposed to equip with ample education and teaching experience and theoretical knowledge when implementing sex education with children, such as Sociology, Pedagogy, Psychology and Children's Psychology. In addition, only by the mutual assistance of homes can teachers' and parents' concepts of sex education be better popularized and children's sex education be correctly guided.

\subsection{Formulate the outline of children's sex education and create an atmosphere of sex education}

In 2011, the State Council issued the “ The Outline of Chinese Children's Development (2011-2020)” and "Including sex and health education into the curriculum system of compulsory education". However, our nation still does not have specific materials for children's sex education at present, let alone the relevant outlines.

It is necessary to regulate a relevant sex education outline, implement universal sex education and make the topic of sex education natural, in order to create an atmosphere of learning sex education in the whole society. Teachers will have the principles to follow with when having children's sex education on the basis of relevant outlines.

\subsection{Offer sex education courses for teachers to improve their professional knowledge}

"The different sexual standard and viewpoints of children in the early period are the precursors of the highly defined concepts and beliefs of adults. This maybe the main factor of adult sexual behaviors and the psychological foundation of many adults' sexual or heart problems. Research in sexual science has also shown that any wrong attitude towards adulthood and sex can be tracked from childhood." [5] Therefore, children's sex education is vital for children's growth and teachers' related theoretical knowledge and practical abilities play and important role in children's growth. But in terms of the current situation in Dalian, teachers training institutions fail to set up specific sex education training courses. So, teachers' professional knowledge level cannot be promoted. And the course training for teacher's sex education should arouse the high attention of related departments.

\subsection{Break the inherent mode and seek new methods of children's sex education}

How to break the inherent concept and seek the new method of children's sex education should attract our constant consideration. Janet s. Hyde believed that cultural differences are directly related to the success of the sex education program. The advocating of sex education should be diversified. Relevant teaching should be made in various aspects according to the development characteristics of children at different ages. Sex education methods in Swedish schools mainly include interpretation, self-study, group discussion and activity-based dialogue to motivate children's learning interest as much as possible. Therefore, innovations must be expressed in teaching methods, such as offering parent-child education courses, making full use of multimedia, using audio-video, picture books and other diversified teaching methods. The new method of pioneering sex education is to refer to the western education idea and create our own teaching methods.

\section{Conclusion}

Sex education is significant for children's healthy growth and kindergarten education. This paper made the research of children's sex equation current situation and problems in Dalian with the method of questionnaire and interview, and put forward countermeasures to promote the development of children's sex education. The research conclusions of this paper mainly consisted of the following four aspects: to deepen the homeland assistance and transform the concepts about sex education of teachers and parents; to make out the related outlines and create the atmosphere; to launch the related courses for teachers and enhance teachers' professional knowledge; to break up the inherent pattern and seek the new methods of 
children's sex education. This paper only selected four kindergartens in Dalian as the survey objects. Due to the small number of samples, the survey result lacked enough representatives, having not enough discussion with children's sex education in kindergartens.

\section{References}

[1]. Ministry of Education. A guide to learning and development for children aged 3-6[M].2012(9).

[2]. Xi Qinglan. Survey of the current situation of 286 children's sex education[J]. Chinese School Doctors. 2005(02)

[3]. Huang Jinhua. Research on the targets and contents of children's sex education[D]. Hunan Normal University 2008.05.

[4]. Huang Junguan and Li Meiling. Existing problems and countermeasures of children's sex education[J]. Journal of Yulin Normal University,2015(3):100-106

[5]. Xu Ying. The inspiration of foreign painted nature education to Chinese children's sex education[J]. Modern Education Science2013(03) 